Bidik

Vol. 1 No. 1 Oktober 2020

$12-17$

\title{
Peningkatan Kemampuan Menulis Laporan Kegiatan Mahasiswa Di Lingkungan Universitas Lancang Kuning
}

\author{
Rosman, $\mathrm{H}^{*}$, Nining Sudiar, Hadira Latiar \\ Fakultas Ilmu Budaya, Universitas Lancang Kuning \\ *Email : rosman20@,unilak.ac.id
}

\begin{abstract}
Activity reports are one of the most important elements in an organization. The activity of writing student activity reports at the end of the implementation of activities becomes a thing that is always avoided by students, especially students who are members of a sub-campus organization. The community service activities aim to provide understanding, as well as improve the ability to write reports on student activities in accordance with the guidelines issued by BPM the Lancang Kuning University. In particular, this activity aims to improve the knowledge and techniques of writing and the preparation of student activity reports especially Organisasi Mahasiswa (ORMAWA) such as DPM, BEM, UKM and HMJ at the Lancang Kuning University. This service activity includes training or counseling which contains the delivery of information for material that is technical and the practice of the report writer, in this case is material about the concept of the report; dialogical method that is question and answer and continues with the practice of writing reports on how to write reports in accordance with the guidelines issued by BPM Lancang Kuning University; and training methods to instill technical and practical skills and skills in writing reports.
\end{abstract}

Keywords: Final Activity Report, Student, Unilak

\begin{abstract}
Abstrak
Laporan kegiatan merupakan salah satu unsur yang paling penting dalam suatu organisasi. Kegiatan penulisan laporan kegiatan mahasiswa diakhir pelaksanaan kegiatan menjadi hal yang selalu dihindari oleh mahasiswa terutama mahasiswa yang tergabung dalam subuah organisasi kampus. Kegiatan pengabdian kepada masyarakat ini bertujuan memberikan pemahaman, serta meningkatkan kemampuan menulis laporan kegiatan kemahasiswaan sesuai pedoman yang dikeluarkan oleh BPM Universtas Lancang Kuning. Adapun secara khusus kegiatan ini bertujuan untuk meningkatkan pengetahuan dan teknik penulisan dan penyusunan laporan kegiatan mahasiswa khsusnya Organisasi Mahasiswa (ORMAWA) seperti DPM, BEM, UKM dan HMJ di lingkungan Universitas Lancang Kuning. Kegiatan pengabdian ini meliputi pelatihan atau penyuluhan yang berisi penyampaian informasi untuk materi yang bersifat teknis dan praktik penulis laporan, dalam hal ini adalah materi tentang konsep laporan; metode dialogis yang bersifat tanya jawab dan dilanjutkan dengan praktek menulis laporan tentang bagaimana menulis laporan yang sesuai dengan pedoman yang dikeluarkan BPM Universitas Lancang Kuning; dan metode pelatihan untuk menanamkan kecakapan dan ketrampilan teknis dan praktis dalam menulis laporan.
\end{abstract}

Kata Kunci: Laporan Akhir Kegiatan, Mahasiswa, Unilak 


\section{Pendahuluan}

Penulisan laporan kegiatan merupakan salah satu bentuk pertanggung jawaban panitia pelaksana kegiatan terhadap pemberi dana maupun instansi yang menaunginya. Tujuan dari laporan kegiatan yaitu memberikan gambaran dan proses pelaksanaan sebuah kegiatan yang sudah dilaksanakan dari sebuah organisasi maupun institusi.

Unilak sendiri setiap kegiatan dapat dilaksanakan oleh sivitas akademika baik dari unsur tenaga pendidik/dosen, tenaga kependidikan/pegawai/staf dan mahasiswa. Setiap unsur tersebut memiliki kewajiban yang sama dalam membuat laporan kegiatan di akhir kegiatan, sebagai bukti telah dilaksanakannya kegiatan dan sebagai pertanggungjawaban dalam penggunaan anggaran yang telah diberikan.

Mahasiswa sebagai salah satu unsur yang memiliki peran penting dalam perguruan tinggi. Menurut Kamus Besar Bahasa Indonesia mahasiswa adalah seseorang yang menuntut ilmu di perguruan tinggi. Di dalam dunia pendidikan, status mahasiswa adalah status tertinggi seorang murid di dunia pendidikan. Sedangkan fungsionaris mahasiswa adalah mahasiswa yang memiliki kedudukan dan fungsi di sebuah organisasi mahasiswa baik itu Himpunan Mahasiswa Jurusan (HMJ), Badan Eksekutif Mahasiswa (BEM), Dewan Perwakilan Mahasiswa (DPM), dan Unit Kegiatan Mahasiswa (UKM) yang ada di lingkungan perguruan tinggi. (Badan Pengambangan dan Pembinaan Bahasa, 2016)

Di Unilak, menulis laporan kegiatan masih menjadi bagian yang kurang diminati oleh sivitas akademika terutama dikalangan mahasiswa. Kegiatan yang dimaksud adalah seluruh aktivitas yang dilaksanakan oleh DPM, BEM, UKM, dan HMJ di tingkat Universitas dan atau fakultas. (Unilak, 2016). Kondisi ini sangat disayangkan mengingat kegiatan penulisan laporan kegiatan merupakan salah satu bentuk monitoring yang sudah menjadi aturan baku Unilak sejak tahun 2016.

Disisi lain, berdasarkan pemantauan yang dilakukan oleh Tim Pelaksana, gairah mahasiswa Unilak untuk membuat laporan kegiatan tersebut masih sangat minim. Bahkan beberapa laporan kegiatan yang sudah ada tidak sesuai dengan format yang sudah ditentukan oleh BPM Unilak.

Permasalahan utama yang dihadapi oleh mitra adalah belum pahamnya mahasiswa dalam membuat laporan kegiatan, sehingga pelatihan tentang peningkatan penulisan laporan mahasiswa Unilak ini diharapkan mampu memberikan kemudahan dalam menulis laporan kegiatan mahasiswa yang sesuai dengan pedoman yang telah dibuat oleh BPM Unilak. Terkait permasalahan tersebut, maka solusi yang ditawarkan adalah diadakannya pelatihan menulis laporan kegiatan yang sesuai dengan buku pedoman Unilak. Diharapkan, hasil kegiatan ini adalah meningkatnya kemampuan mahasiswa dalam membuat laporan kegiatan yang sesuai dengan pedoman Unilak.

\section{Pedekatan Pelaksanaan Program}

Kegiatan pengabdian ini diperuntukkan seluruh Organisasi Mahasiswa (ORMAWA) di lingkungan Universitas Lancang Kuning. Pelaksanaan kegiatan meliputi beberapa tahap sebagai berikut:

1. Pengenalan laporan kegiatan mahasiswa 
Pada tahap ini, tim pelaksana mengenalkan tentang konsep laporan kegiatan mahasiswa. Hal ini penting dilakukan untuk menyamakan persepsi tentang laporan kegiatan Materi yang disampaikan pada tahap ini adalah:

- Konsep laporan kegiatan

- Format laporan kegiatan

- Jenis-jenis laporan kegiatan

Peralatan yang dibutuhkan:

- Handout contoh laporan kegiatan

- Power Point

- Laptop

2. Pengenalan pedoman laporan kegiatan

Pada tahap ini, tim pelaksana memperkanalkan pedoman laporan kegiatan Unilak. Materi yang disampaikan adalah:

- Buku pedoman laporan kegiatan mahasiswa

- Format pedoman

Peralatan yang dibutuhkan:

- Contoh laporan yang sesuai dengan buku pedoman Unilak

- Laptop

3. Praktik menulis laporan kegiatan mahasiswa

Pada tahap ini, tim pelaksana bersama dengan peserta melakukan praktik menulis laporan kegiatan mahasiswa sesuai format pedoman. Materi yang disampaikan:

- pedoman

- Praktik penulisan laporan kegiatan

Peralatan yang dibutuhkan:

- Laptop

- Buku pedoman penulisan laporan kegiatan

\section{Pelaksanaan Program}

Kegiatan pengabdian kepada masyarakat yang diwujudkan dalam bentuk kegiatan pelatihan peningkatan penulisan laporan kegiatan mahasiswa di lingkungan Universitas Lancang Kuning ini telah selesai dilaksanakan secara keseluruhan. Kegiatan ini diikuti oleh Organisasi Mahasiswa (ORMAWA) di lingkungan Unilak. Antusiasme peserta kegiatan terlihat dari minat dan semangat yang tercermin selama pelatihan berlangsung. 


\section{Gambar 1 Peserta pelatihan sedang mendengarkan materi}

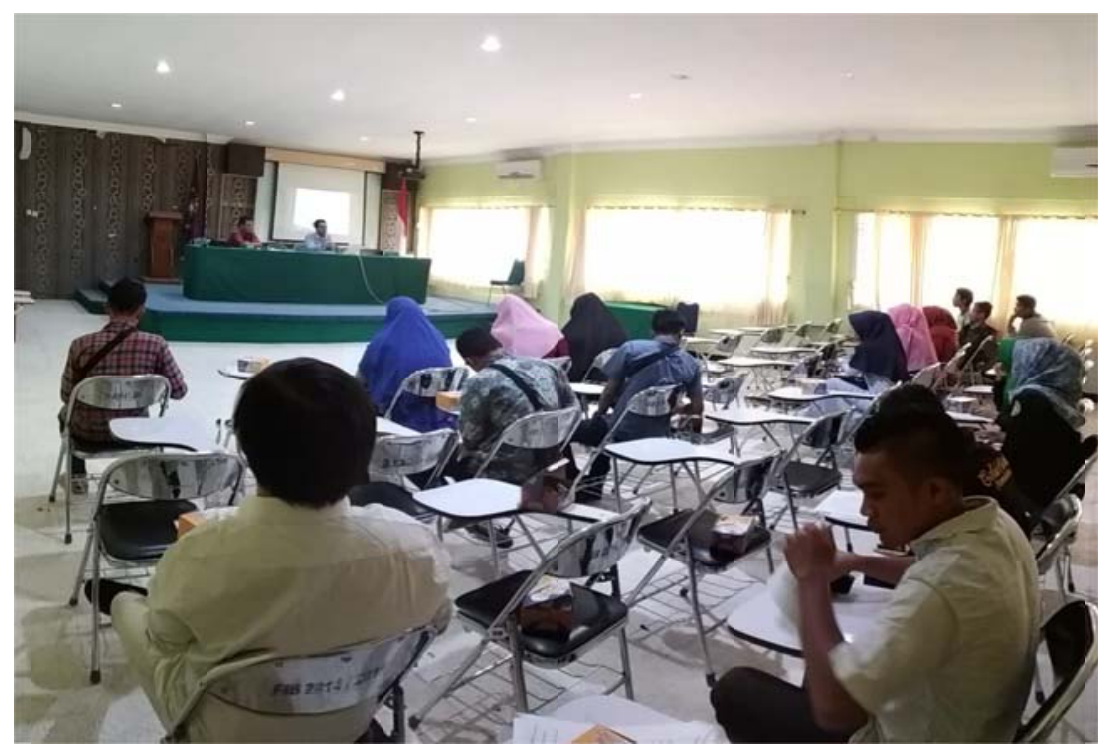

Pada tahap awal, kegiatan ini diawali dengan pengenalan laporan kegiatan mahasiswa. Sesi ini berisi tentang penjelasan umum terkait konsep laporan kegiatan, seperti pengertian, fungsi, serta tujuan penulisan laporan kegiatan. Penjelasan tersebut bertujuan untuk memberikan gambaran kepada peserta pengabdian bahwa penulisan laporan mahasiswa merupakan suatu keharusan.

Selain penjelasan umum terkait konsep laporan kegiatan mahasiswa, peserta juga dibekali dengan penjelasan tentang format laporan kegiatan. Kegiatan yang dijelaskan adalah menjelaskan format laporan kegiatan yang baik dan benar menuruat pedoman yang dibuat oleh BPM Unilak. Peserta juga diberi kesempatan untuk melakukan tanya jawab terkait penulisan laporan kegiatan dengan tim pengabdian. Melalui tanya jawab tersebut, tim pengabdian memperoleh beberapa temuan. Pertama, mahasiswa belum mengetahui adanya buku pedoman penulisan laporan kegiatan yang dikeluarkan oleh BPM Unilak. Kedua, mahasiswa menggunakan laporan yang dibuat oleh sebelumnya sebagai pedoman penulisan laporan. Ketiga, format serta isi laporan kegiatan yang dibuat tidak sesuai dengan pedoman dari BPM Unilak. Keempat, masih adanya Organisasi Mahasiswa yang belum membuat laporan kegiatan terkait kegiatan yang telah dilaksanakan. Dari hasil temuan tersebut tim pelaksana dapat menyimpulkan bahwa sebagian besar mahasiswa belum memahami cara membuat laporan kegiatan yang baik dan benar sesuai buku pedoman yang dibuat oleh BPM Unilak, serta dalam kegiatan pelatihan ini peserta sangat antusias dalam mengikuti rangakaian kegiatan. 


\section{Gambar 2 Pemateri sedang memaparkan materi pelatihan}

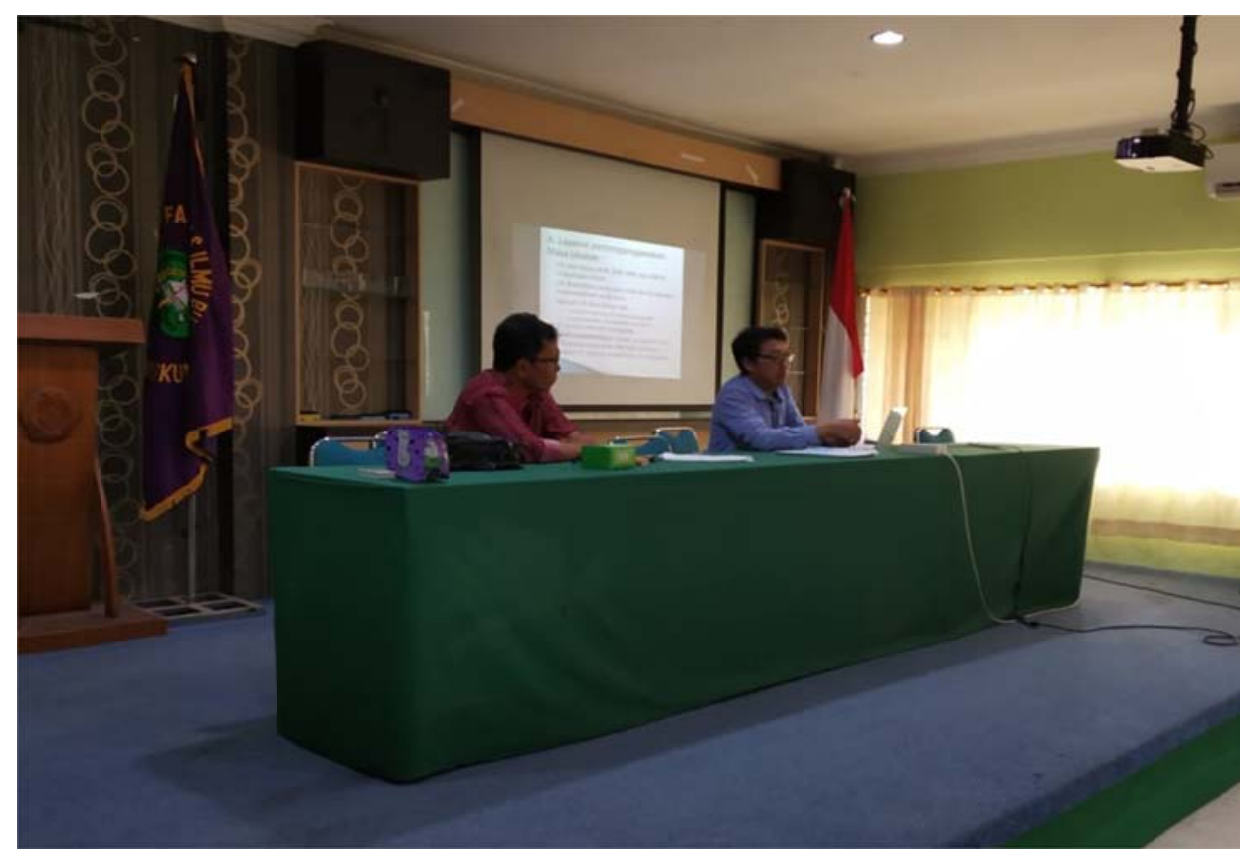

Tahap selanjutnya adalah tahap praktik. Pada tahap ini peserta diberi contoh format pedoman penulisan laporan kegiatan yang diterbitkan oleh BPM Unilak. Peserta juga diajak bersama-sama untuk praktik langsung menulis laporan kegiatan sesuasi dengan buku pedoman.

Selain melibatkan institusi mitra, pengabdian ini juga melibatkan mahasiswa Program Studi Ilmu Perpustakaan Fakultas Ilmu Budaya Universitas Lancang Kuning. Jumlah mahasiswa yang terlibat langsung dalam kegiatan ini adalah 3 orang. Keterlibatan mahasiswa ini merupakan bentuk pelibatan mahasiswa dalam pengabdian kepada masyarakat. Hal tersebut bertujuan agar mahasiswa mampu memahami bahwa kewajiban mereka tidak hanya belajar di kelas saja, tetapi juga melakukan kegiatan pengabdian kepada masyarakat.

\section{Gambar 3 Keterlibatan mahasiswa dalam kegiatan pengabdian}

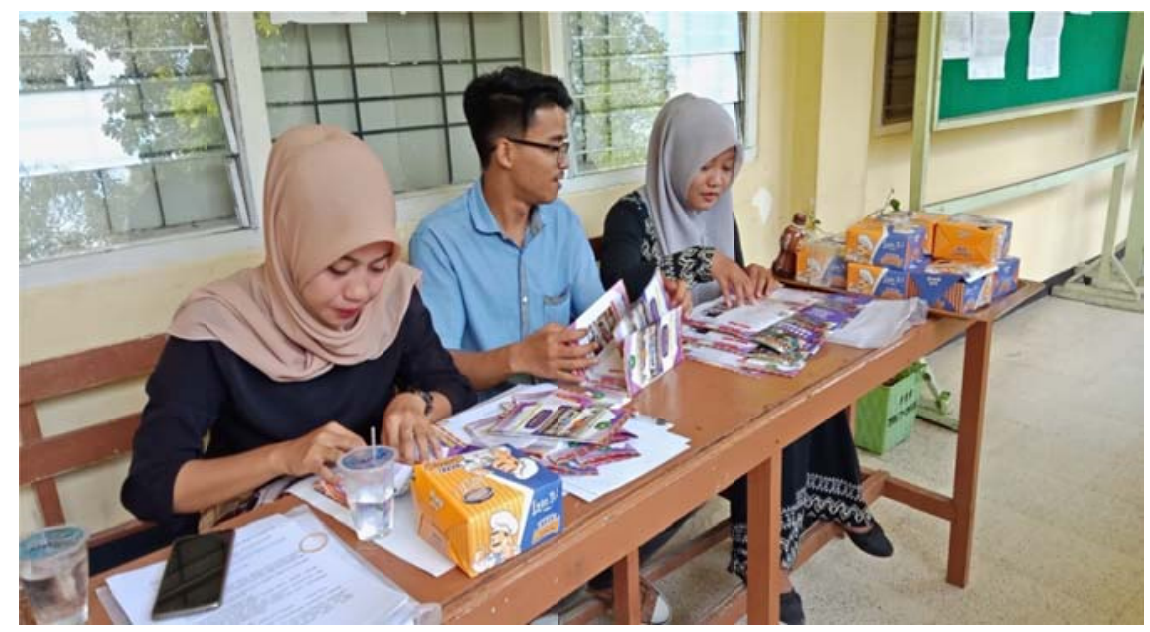


Peningkatan pemahaman dan keterampilan masyarakat yang dimaksudkan adalah pemahaman dan keterampilan terkait penulisan laporan kegiatan mahasiswa. Berdasarkan hasil evaluasi menggunakan angket pretest dan posttest, diperoleh informasi bahwa peserta yang ikut dalam kegiatan pengabdian telah mengalami peningkatan pemahaman dan keterampilan penulisan laporan kegiatan mahasiswa. Hal tersebut dapat dilihat dari nilai angket pretest dan post test pada tabel berikut ini:

\section{Tabel 1 Evaluasi Pretest dan Post test}

\begin{tabular}{|c|c|c|c|c|}
\hline No. & Materi & Pretest & $\begin{array}{c}\text { Post } \\
\text { test }\end{array}$ & Peningkatan \\
\hline 1. & $\begin{array}{l}\text { Pemahaman tentang } \\
\text { laporan kegiatan } \\
\text { mahasiswa }\end{array}$ & $56,00 \%$ & $80,00 \%$ & $24,00 \%$ \\
\hline 2. & $\begin{array}{l}\text { Kemampuan menulis } \\
\text { laporan kegiatan } \\
\text { sesuai dengan } \\
\text { pedoman Unilak }\end{array}$ & $61,73 \%$ & $88,67 \%$ & $26,94 \%$ \\
\hline
\end{tabular}

Berdasarkan tabel di atas dapat dilihat bahwa seluruh materi yang disampaikan dapat dipahami dengan baik oleh peserta kegiatan. Peserta telah memiliki peningkatan pemahaman sebesar 24,00\% pada materi pemahaman tentang laporan kegiatan mahasiswa. Sedangkan pada materi Kemampuan menulis laporan kegiatan sesuai dengan pedoman Unilak, peserta memiliki peningkatan pemahaman serta keterampilan sebesar $26,94 \%$.

\section{Refleksi Capaian Program}

Berdasarkan pemaparan hasil kegiatan di atas, dapat disimpulkan bahwa seluruh target luaran yang direncanakan telah tercapai dengan baik. Hal ini dapat terlihat dari adanya peningkatan pemahaman dan keterampilan peserta kegiatan terkait kemampuan menulis laporan kegiatan mahasiswa. Indikator lainnya adalah terlah tersubmit artikel ilmiah dari kegiatan yang telah dilaksanakan.

\section{Penutup}

Hasil kegiatan pelatihan ini agar diimplementasikan oleh mahasiswa pada organisasi masing-masing. Mengingat minimnya pelatihan-pelatihan kemahasiswaan dan pengembangan lainnya di wilayah mitra program pengabdian, maka tim pelaksana menilai perlu diadakannya pelatihan lain bagi mahasiswa Unilak.

\section{Daftar Pustaka}

Badan Pengambangan dan Pembinaan Bahasa, K. (2016). Kamus Besar Bahasa Indonesia. Jakarta: Kementrian Pendidikan dan Kebudayaan RI.

Lasa HS. (2009). Kamus Kepustakawanan Indonesia. Yogyakarta: Pustaka Book Publisher.

Syahdan. (2009). Membentuk Paradigma Gemar Menulis di Usia Dini dalam Konteks 
Rosman H, Nining Sudiar, Hadira Latiar-Peningkatan Kemampuan Menulis... | 54

Kurikulum Pendidikan Nasional. Jurnal Ilmu Budaya, Vol. 6, No. 1 Agustus 2009.

Unilak, B. P. (2016). Pedoman Penulisan Laporan Pejabat Struktural. Pekanbaru: BPM Universitas Lancang Kuning. 